\title{
Limited impact of an invasive oyster on intertidal assemblage structure and biodiversity: the importance of environmental context and functional equivalency with native species
}

\author{
Nadescha Zwerschke ${ }^{1}$ (1) $\cdot$ Philip R. Hollyman ${ }^{1} \cdot$ Romy Wild $^{1} \cdot$ Robin Strigner $^{1} \cdot$ John R. Turner ${ }^{1}$ Jonathan W. King ${ }^{2}$
}

Received: 8 November 2017 / Accepted: 28 March 2018 / Published online: 20 April 2018

(c) The Author(s) 2018

\begin{abstract}
Impacts of invasive species are context dependent and linked to the ecosystem they occur within. To broaden the understanding of the impact of a globally widespread invasive oyster, Crassostrea (Magallana) gigas, intertidal surveys were carried out at 15 different sites in Europe. The impact of $C$. gigas on macro- (taxa surrounding oyster $>1 \mathrm{~cm}$ ) and epifaunal (taxa on oyster $<1 \mathrm{~cm}$ ) benthic communities and $\alpha$ and $\beta$-diversity was assessed and compared to those associated with native ecosystem engineers, including the flat oyster Ostrea edulis. Whilst the effect of $C$. gigas on benthic community structures was dependent on habitat type, epifaunal communities associated with low densities of $O$. edulis and $C$. gigas did not differ and changes in benthic assemblage structure owing to the abundance of $C$. gigas were therefore attributed to the presence of oyster shells. Macrofaunal $\alpha$-diversity increased with $C$. gigas cover in muddy habitats, while epifaunal $\alpha$-diversity decreased at greater oyster densities. Macrofaunal $\beta$-diversity was greatest at low densities of $C$. gigas; however, it did not differ between samples without and increased densities of oysters. In contrast, epifaunal $\beta$-diversity decreased with increasing oyster cover. Different environmental contexts enabled more independent predictions of the effect of $C$. gigas on native communities. These were found to be low and more importantly not differing from $O$. edulis. This indicates that, at low densities, $C$. gigas may be functionally equivalent to the declining native oyster in terms of biodiversity facilitation and aid in re-establishing benthic communities on shores where $O$. edulis has become extinct.
\end{abstract}

\section{Introduction}

Globalisation and climate change have accelerated the spread of invasive species, which are typically associated with loss of diversity, alterations of ecosystem services and displacement of native species (Vitousek 1990; Vitousek et al. 1996, Butchart et al. 2010; Bellard et al. 2013). Some

Responsible Editor: S. Shumway.

Reviewed by F. O'Beirn and an undisclosed expert.

Electronic supplementary material The online version of this article (https://doi.org/10.1007/s00227-018-3338-7) contains supplementary material, which is available to authorized users.

Nadescha Zwerschke

nzwerschke01@qub.ac.uk

1 School of Ocean Sciences, Bangor University, Menai Bridge, Anglesey LL59 5AB, UK

2 Centre for Applied Marine Sciences, Bangor University, Menai Bridge, Anglesey LL59 5AB, UK invasive species are ecosystem engineers and are capable of actively altering the habitat of the recipient communities (Jones et al. 1997; Crooks 2002). The impact of such invasive ecosystem engineers is not always clear, since additional structure and shelter, like those provided by invasive reef builders, affect biotic interactions, biodiversity and other ecosystem processes in different ways (Crooks 2002; Bouma et al. 2009; Katsanevakis et al. 2014; Guy-Haim et al. 2018). The lack of unified methods to identify adverse effects of non-native species, in combination with studies carried out on small localised scales, hampers efforts to generalise predictions of impacts of non-native species over broader spatial scales (Thomsen et al. 2011; Kumschick et al. 2015). Negative impacts of invasive species are often found on small localised scales, but these do not represent spatial variability and context dependency of invasion effects accurately (Fridley et al. 2007; Hulme and Barrett 2013). Surveys and experimental studies on the impact of invasive species are generally driven by different hypotheses within different environmental contexts and thus results are often not comparable (Kumschick et al. 2015). To allow for more 
ubiquitous predictions to be made, which pinpoint areas of concern and help to more efficiently guide conservation measures, comparable surveys have to be carried out over broader spatial scales incorporating a variety of different environmental contexts (Kumschick et al. 2015).

The Pacific oyster Crassostrea gigas (Magallana gigas; Salvi and Mariottini 2016; Bayne et al. 2017) has been introduced to Europe, the Americas and Australia as an alternative to declining native oyster fisheries and has since established extensive wild, self-sustaining populations (Eno et al. 1997; Shatkin et al. 1997). Being extremely versatile, $C$. gigas usually occurs within the mid to low intertidal zone over a range of different habitats, such as estuaries, sea loughs and exposed rocky shores in which it creates a novel biogenic reef habitat (Kochmann et al. 2013). It was expected that the spread of $C$. gigas in introduced areas was limited owing to an insufficient number of days at which seawater reaches the range of temperatures $\left(15-25{ }^{\circ} \mathrm{C}\right)$ required for conditioning, larvae survival and settlement of spat (Child and Laing 1998; Syvret et al. 2008). Predicted increases in seawater temperature caused by global warming, however, may increase and accelerate its spread (Rinde et al. 2016; Robins et al. 2017). Areas with dense populations of $C$. gigas report differing consequences of its abundance (Herbert et al. 2016). For example, in Australia, it is predicted that $C$. gigas may displace the native Sydney rock oyster in both mid and low intertidal zones (Krassoi et al. 2008) where it also alters native species assemblages (Wilkie et al. 2012). Within Europe, C. gigas is thought to limit the abundance of another ecosystem engineer, the protected honeycomb worm Sabellaria alveolata (Dubois et al. 2006; Green and Crowe 2013) and has the potential to displace the native flat oyster Ostrea edulis (Laugen et al. 2015; Zwerschke et al., unpublished data). Previously, it was thought that habitats of $O$. edulis and $C$. gigas did not overlap; however, recent surveys show that both species co-occur at similar shore heights (Laugen et al. 2015; Zwerschke et al. 2017). So far, juvenile oyster clusters of both species have been found to support similar species assemblages and diversity on hard substratum (Zwerschke et al. 2016). Yet, it is unclear whether species assemblages and diversity would differ between $C$. gigas and $O$. edulis in different habitat types or in mature oyster beds owing to more pronounced differences in morphology and life history traits of each oyster species (Mann 1979; Green 2017; Nielsen et al. 2017).

Over the last decade, several surveys have been carried out in the NE Atlantic to quantify the impact of $C$. gigas on diversity and benthic assemblage structure (Herbert et al. 2016). One of the more extensive surveys destructively sampled $50 \mathrm{~m}^{2}$ oyster reefs on rocky as well as muddy substratum to assess macrofaunal abundance and species richness at two locations on the west coast of France (Lejart and Hily 2011). Oyster reef assemblages were compared to those found on bare substratum of an equal area or within soft sediment and were found to be greater in macrofaunal abundance within $C$. gigas reefs on both rocky and muddy substratum (Lejart and Hily 2011). Additionally, the relative abundance of functional groups was altered by $C$. gigas (Lejart and Hily 2011). In Sweden and the Dutch and German Wadden Sea, experimental studies and surveys were carried out to compare $\alpha$-diversity and macrofaunal assemblages associated with $C$. gigas reefs to those associated with a native ecosystem engineer, the blue mussel Mytilus edulis (Kochmann et al. 2008; Markert et al. 2009; Hollander et al. 2015). Their findings concurred in so far as they found differences in macrofaunal assemblages between both ecosystem engineers, owing to structural differences between oysters and mussels, but differed in the key species driving these shifts (Kochmann et al. 2008; Markert et al. 2009; Hollander et al. 2015).

Impacts of globally established $C$. gigas populations have been widely regarded as potentially harmful to the ecosystem (Herbert et al. 2016). Few studies, however, have aimed to identify a context independent effect of $C$. gigas on assemblage structure and biodiversity by including different geographical regions and ecosystems in their approach. It remains unclear whether the altering degrees of severity of impacts caused by C. gigas (Kochmann et al. 2008; Markert et al. 2009; Zwerschke et al. 2016) are owing to different abiotic and biotic conditions or differing methods between studies. In the present study, we aimed to gain a clearer understanding of the impact of $C$. gigas on benthic assemblages as well as $\alpha$-diversity (species richness and their relative abundance in one community) and $\beta$-diversity (diversity between communities; Gray 1997) within different environmental contexts (sensu Padilla 2010) in different geographical regions. Such a comprehensive survey will help to identify context-independent impacts of $C$. gigas on invaded ecosystems that are only visible over a broader scale such as changes in $\beta$-diversity (Green and Crowe 2014) or alterations in species distributions across shores. This systematic assessment was carried out at 15 sites across the UK, Ireland and France and it was expected that habitat alterations due to ecosystem engineering capacity of $C$. gigas alters (i) macro and epifaunal assemblage structure within sites by changing the abundance of key species and (ii) biodiversity, regardless of the habitat type. It was further hypothesised that (iii) where $C$. gigas and $O$. edulis co-occurred, epifaunal assemblages supported by both species would differ and (iv) occurrence of $C$. gigas over a broad scale would reduce $\beta$-diversity by creating similar biogenic reef habitats across different substratum types. 


\section{Methods}

Wild populations of $C$. gigas in Europe occur along a latitudinal gradient between the Shetland islands and the Mediterranean Sea (Herbert et al. 2016; Shelmerdine et al. 2017). In this study, 15 sites across the UK, Ireland and Northern France were visited from May to July 2011 (Fig. 1, Table 1), to represent some of this latitudinal variation $(1000 \mathrm{~km} \times 650 \mathrm{~km}$ range). Sites were chosen based on Lallias et al. (2015) and local knowledge of oyster populations from a range of stakeholders (see "Acknowledgements").

\section{Shore survey}

Ecological surveys over a variety of habitats are necessarily associated with a high degree of biological and abiotic variability. To capture abiotic factors most likely to drive differences in oyster abundances and assemblage structure, each site was assessed in a similar manner upon arrival on the shore. The type of substrate at each site was classified into four categories (mud, rock, gravel/boulders and mussel bed). Substratum type and abundance of dominant species were used to categorise wave exposure for individual sites (low, medium, high) according to the exposure scale by Ballantine (1961). The shore height above Chart Datum at which the oysters were present was estimated using a surveyor's level (Leica NA 820, $n=5$ ); the maximum and minimum heights on the shore at which oysters were found were also measured. The topography of each site was quantified using rugosity measurements whereby a $5 \mathrm{~m}$ chain $\left(L_{\mathrm{g}}\right)$ was laid over the substrate, taking into account all fluctuations in surface level and measuring the resulting straight line distance that was covered by the chain $\left(L_{\mathrm{r}}\right)$ (Nic et al. 1997). Rugosity was then calculated according to the following equation:

$f_{\mathrm{r}}=\frac{L_{\mathrm{r}}}{L_{\mathrm{g}}}$.

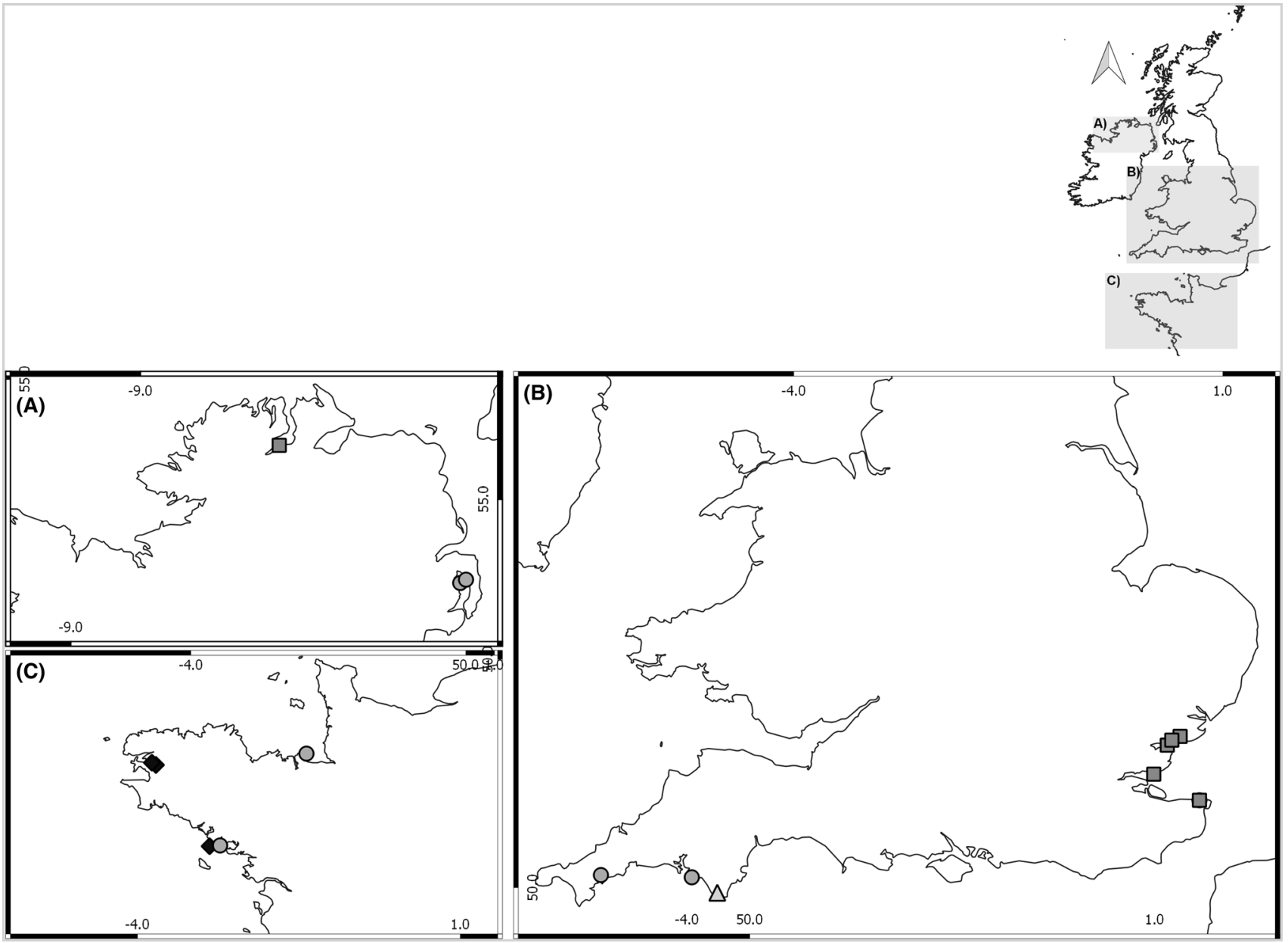

Fig. 1 Locations of sites surveyed. Mean oyster abundance at each site was classified into the SACFOR scale (Hiscock 1996; Connor et al. 2004) [superabundant $>100$ oysters $/ \mathrm{m}^{2}$ (black diamond), abun- dant $=10-99$ oysters $/ \mathrm{m}^{2}$ (dark grey square) common $=1-9$ oysters $/ \mathrm{m}^{2}$ (grey circle) and frequent $=0.1-0.9$ oysters $/ \mathrm{m}^{2}$ (light grey triangle) $]$ 
Table 1 Surveyed sites, their geographical location and physical attributes where the presence of $C$. gigas and $O$. edulis in brackets and italics $\left(\mathrm{mean} / \mathrm{m}^{2} \pm \mathrm{SD}\right)$ was detected

\begin{tabular}{|c|c|c|c|c|c|c|c|c|c|}
\hline \multirow[t]{2}{*}{ Location } & \multirow[t]{2}{*}{ Site } & & \multirow{2}{*}{$\begin{array}{l}\text { Height } \\
(\text { mean } \pm \mathrm{SD})\end{array}$} & \multirow{2}{*}{$\begin{array}{l}\text { Rugosity } \\
(\text { mean } \pm \mathrm{SD})\end{array}$} & \multicolumn{2}{|c|}{ Coordinates } & \multirow{2}{*}{$\begin{array}{l}\text { C. gigas }(\text { O. edulis) abun- } \\
\text { dance }\left(\mathrm{mean} / \mathrm{m}^{2} \pm \mathrm{SD}\right)\end{array}$} & \multirow[t]{2}{*}{ Substratum } & \multirow[t]{2}{*}{ Wave exposure } \\
\hline & & & & & Latitude & Longitude & & & \\
\hline Cornwall, UK & Turnaware Point & & $1.54 \pm 0.31$ & $0.81 \pm 0.08$ & 50.2034 & -5.0338 & $1.29 \pm 1.67$ & Rocky & Medium \\
\hline Devon, UK & Noss Mayo & & $1.89 \pm 0.25$ & $0.75 \pm 0.09$ & 50.3117 & -4.0628 & $6.14 \pm 4.06$ & Rocky & Medium \\
\hline Devon, UK & Snapes Point & & $1.61 \pm 0.06$ & $0.76 \pm 0.10$ & 50.2396 & -3.7600 & $0.86 \pm 0.80$ & Rocky & Medium \\
\hline Essex, UK & Bradwell & & $0.76 \pm 0.10$ & $0.82 \pm 0.04$ & 51.7347 & 0.8860 & $74.57 \pm 52.06$ & Muddy & Low \\
\hline Essex, UK & Brightlingsea & & $0.49 \pm 0.25$ & $0.76 \pm 0.05$ & 51.8062 & 1.0164 & $52.29 \pm 20.70$ & Muddy & Low \\
\hline Essex, UK & Southend on Sea & LS & $0.26 \pm 0.03$ & $0.94 \pm 0.03$ & 51.5235 & 0.7760 & $32.86 \pm 31.05$ & Muddy & Low \\
\hline Essex, UK & Southend on Sea & HS & $1.70 \pm 0.03$ & $0.99 \pm 0.01$ & 51.5235 & 0.7760 & $23.43 \pm 15.65$ & Gravel & Low \\
\hline Essex, UK & West Mersea & & $2.16 \pm 0.51$ & $0.82 \pm 0.05$ & 51.7734 & 0.9295 & $76.57 \pm 64.35$ & Muddy & Low \\
\hline Brittany, France & Cancale & & $2.21 \pm 1.28$ & $0.74 \pm 0.08$ & 48.7022 & -1.8453 & $5.86 \pm 4.80$ & Rocky & High \\
\hline Brittany, France & Le Faou & & $0.42 \pm 0.73$ & $0.92 \pm 0.03$ & 48.2966 & -4.2197 & & Muddy & Low \\
\hline Brittany, France & Moulin-Mer & & $1.46 \pm 0.86$ & $0.80 \pm 0.08$ & 48.3120 & -4.2910 & $248.86 \pm 102.53$ & Rocky & Low \\
\hline Brittany, France & Penthievre & & $3.21 \pm 0.23$ & $0.83 \pm 0.03$ & 47.5419 & -3.1333 & $117.43 \pm 88.61$ & Rocky & High \\
\hline Brittany, France & St. Philibert & & $0.21 \pm 0.23$ & $0.99 \pm 0.00$ & 47.5703 & -2.9705 & $4.57(3.86) \pm 3.49 \quad(2.25)$ & Gravel & Low \\
\hline Kent, UK & Birchington & LS & $0.74 \pm 0.05$ & $0.90 \pm 0.01$ & 51.3819 & 1.3157 & $32.29 \pm 22.79$ & Mussel bed & Medium \\
\hline Kent, UK & Birchington & HS & $2.18 \pm 0.09$ & $0.85 \pm 0.04$ & 51.3819 & 1.3157 & $2.43 \pm 1.94$ & Rocky & Medium \\
\hline Donegal, Ireland & Lough Swilly & LS & $0.25 \pm 0.07$ & $0.93 \pm 0.01$ & 55.0209 & -7.5774 & $7.00(1.57) \pm 2.76(1.98)$ & Gravel & Low \\
\hline Donegal, Ireland & Lough Swilly & HS & $0.74 \pm 0.09$ & $0.93 \pm 0.01$ & 55.0209 & -7.5774 & $38.00 \pm 10.90$ & Mussel bed & Low \\
\hline Down, UK & Mount Stewart & & $0.64 \pm 0.25$ & $0.93 \pm 0.03$ & 54.5418 & -5.6044 & $1.57(0.53) \pm 1.72(0.49)$ & Gravel & Low \\
\hline Down, UK & Paddies Point & & $0.70 \pm 0.31$ & $0.94 \pm 0.05$ & 54.5178 & -5.6504 & $1.43(0.29) \pm 2.00(0.49)$ & Gravel & Low \\
\hline
\end{tabular}

Mean abundance of $C$. gigas (O. edulis) was calculated using data collected from all quadrats (control and those containing $C$. gigas) within each shore. If two distinct oyster populations were found at high (HS) and low (LS) positions on the shore, both were sampled as independent sampling events. The numbers in italic and brackets denote densities of the second oyster species $O$. edulis

A total of six rugosity measurements were taken at each site, three parallel to and three perpendicular to the shoreline.

\section{Oyster density and macrofauna}

To efficiently assess potential interaction between $C$. gigas densities and macrofaunal assemblages and biodiversity, $3050 \times 50 \mathrm{~cm}$ photo-quadrats were recorded on each site, placed randomly within the identified $C$. gigas zone and photographed (Nikon D90). Percentage abundance and presence of all species visible on the photograph of the quadrat (generally all species $>1 \mathrm{~cm}$ ) were quantified. Abundance of $O$. edulis was limited on shores and was only rarely found in random samples. Thus, to ensure a consistent baseline to which macrofaunal assemblages associated with $C$. gigas could be compared to across sites, we recorded an additional ten haphazardly placed photo-quadrats in areas between $C$. gigas clumps that, purposefully, did not contain any non-native oysters on every site $\left(N_{\text {control quadrats/site }}=13.5 \pm 9.2\right.$ mean \pm SD $)$. On sites with distinctly separated $C$. gigas populations at high and low intertidal areas, both zones were sampled as two independent sampling events to accurately represent the associated species assemblages.

\section{Epifauna}

To estimate interaction between $C$. gigas and species living on and within the oyster shell (individuals $<1 \mathrm{~cm}$ ), 50 oysters were randomly collected from each shore and stored in cool boxes, thereby also preventing the possible loss of any mobile epifauna. Within $24 \mathrm{~h}$ of collection of oysters, epifaunal assemblages were sampled by firstly removing mobile organisms with pressurised freshwater over a $500 \mu \mathrm{m}$ sieve and secondly removing remaining species manually with tweezers. Individual oysters were then photographed (front and back) for subsequent identification of sessile epifauna, which could not be sampled without destroying the organism. All epifaunal species collected from all 50 oysters were pooled in one sample which was analysed for species presence and abundance. Whenever possible, species assemblages and abundances associated with other ecosystem engineers from the same site such as, $O$. edulis and the blue mussel $M$. edulis were used as control. On sites where native European oyster, O. edulis populations were present (Paddies Point, Mount Stewart, Lough Swilly and St. Philibert, Table 1), the sampling procedure for epifauna 
was repeated as outlined above with 50 O. edulis. Owing to a severe decline of $O$. edulis populations in recent years, we could only locate the native oyster at these four locations. Only two sites were identified where $C$. gigas was present in $M$. edulis beds (Birchington and Lough Swilly). Here, a $30 \times 30 \mathrm{~cm}$ quadrat was placed haphazardly over the mussel community without oysters. The mussels contained within the quadrat were removed and treated the same way as the oysters to estimate abundance and identify all associated epifaunal species. The amount of mussels sampled corresponded to the approximate amount of three-dimensional structures provided by the 50 sampled oysters. All epifaunal samples were preserved in $70 \%$ IMS and later identified to the lowest possible taxonomic level.

\section{Image analysis}

Photo analysis was undertaken in Image J (Ferreira and Rasband 2011) where percentage cover and presence of each species in the image was recorded for macrofaunal (quadrats) and epifaunal (oysters) analysis, respectively. The abundance of $C$. gigas, estimated from photo-quadrats, was standardised to mean oyster abundance $/ \mathrm{m}^{2}$ and categorised using the SACFOR scale (superabundant $>100$ oysters $/ \mathrm{m}^{2}$, abundant $=10-99$ oysters $/ \mathrm{m}^{2}$, common $=1-9$ oysters $/ \mathrm{m}^{2}$, frequent $=0.1-0.9$ oysters $/ \mathrm{m}^{2}$, occasional $=0.01-0.09$ oysters $/ \mathrm{m}^{2}$ and rare $<0.009$ oysters $/ \mathrm{m}^{2}$; Hiscock 1996; Connor et al. 2004). This was done for individual photo-quadrats (analysis of macrofauna: number of oysters in a quadrat) and for each sampled site (analysis of epifauna: number of oysters in all 30 quadrats $/ \mathrm{m}^{2}$ covered by sampled quadrats). Because oysters were either not present or were present in numbers $\geq 1$ in photo-quadrats, the abundance of oyster for macrofaunal analysis could not be classified as lower than common. Unfortunately, adequate image analysis was not possible at one site, Le Faou in Brittany, France, owing to the high abundance of Ulva lactuca and Porphyra sp., which covered benthic assemblages completely and would have caused an inaccurate assessment of benthic assemblage structure.

\section{Statistical analysis}

For statistical analysis, C. gigas was not included as a response variable to avoid confounding independent and dependent variables (Huston 1997). Permutational analysis of variance (PERMANOVA; McArdle and Anderson 2001) was used to assess the impact of oyster abundance [macrofauna: absent ( $C$. gigas was not present in quadrat), common, abundant, superabundant; epifauna: control (species assemblages collected from $O$. edulis and M. edulis), frequent, common, abundant, superabundant], habitat type (rock, gravel/boulders, mussel bed and mud) and wave exposure (low, medium, high) on both macro- and epifaunal assemblages. Factors were nested in sampling sites to account for dependencies of replicates from the same shore. Multivariate analysis were based on Bray-Curtis similarity matrices calculated from untransformed and fourth-roottransformed data to distinguish between the effects of rare and dominant species (Clarke and Warwick 2001) and was carried out under a reduced model with 9999 permutations of the residuals. The robustness of PERMANOVA has been shown to be affected by heterogeneity of multivariate dispersions in combination with an unbalanced sampling design, e.g. a varying amount of replicates for each factor combination (Online Resource 1), in which case a greater tendency to type I errors was observed (Anderson and Walsh 2013). Multivariate heteroscedasticity within explanatory variables was tested for by using the function betadisper (R-package vegan; Oksanen et al. 2017). Unfortunately, multivariate dispersion was not homogenous and could not be altered by applying transformations to either macrofaunal or epifaunal datasets. Owing to a lack of an alternative multivariate test, we proceeded with the analysis in PERMANOVA, but altered our $\alpha$-level to a more conservative $P=0.01$. PERMANOVA was also used to test for differences in epifaunal species assemblages associated with $O$. edulis and $C$. gigas at the four sites where both oysters co-occurred in the intertidal zone (Paddies Point, Mount Stewart, Lough Swilly and St. Philibert). Here, the factors oyster species (O. edulis and $C$. gigas) and oyster abundance were again nested in sampling site. Pairwise post hoc tests, using a Bonferroni correction, were carried out to differentiate between treatments within significant factors.

Similarity of percentage (SIMPER) analysis was used to identify the most important taxa driving differences between groups of significant factors such as oyster abundance and habitat type. A $90 \%$ cutoff was used for the cumulative dissimilarity between groups, because thereafter remaining taxa individually contributed to $<2 \%$ of overall differences in assemblage structure. Differences in the abundances of these taxa were analysed with a generalised linear mixed model (GLMM) using penalised quasi-likelihood (PQL) to estimate interference and fitted with a normal or lognormal distribution as dictated by data (Breslow 2003). Factors shown to be significant in the PERMANOVA analysis, such as oyster abundance and habitat type for macrofauna, were added as fixed factors, while sampling site was added as random factor to account for nested data. Least-square means, where $P$-values were adjusted for the Tukey method, were applied as post hoc test to differentiate between significant terms (Lenth 2016).

The Shannon-Weaver index was used to calculate $\alpha$-diversity for macro- and epifauna. The most appropriate factors describing distribution of diversity were chosen by including all available factors (oyster abundance, habitat 
type, exposure, shore rugosity, height on shore, latitude) in a linear model and randomly dropping interactions and factors from the model and comparing it to the original model using $P$-values of ANOVA (analysis of variance; Zuur et al. 2009). The final model was tested using GLMM with PQL to estimate interference and was fitted with a normal distribution. For macrofaunal diversity, the fixed factors oyster abundance, habitat type and exposure and the random factor sampling site were included in the analysis. For epifaunal diversity, only the fixed factors oyster abundance and habitat type were included in the analysis. Here, latitude was included as random factor to account for spatial variability and nestedness of samples from similar areas, since replication of epifaunal diversity per site was low [ 1 factor combinations/site (2, when control values were included)]. To test for the effect of $C$. gigas on epifaunal diversity, $\alpha$-diversity associated with $O$. edulis and $M$. edulis beds was included in the analysis as control variable. To clearly differentiate whether alternating effects of oyster species on biodiversity exist, a subsequent analysis, limited to the four sites were $O$. edulis and C. gigas co-existed, tested for the effect of oyster identity and oyster abundance on diversity, including site as random factor. Homogeneity of variance and normal distribution of residuals from each model were assessed visually to guarantee that data fit the model (Zuur et al. 2009). Least-square means, where $P$-values were adjusted for the Tukey method, were applied as post hoc test to differentiate between significant terms.

To estimate whether $\beta$-diversity changes with increasing oyster abundance, local contribution to $\beta$-diversity (LCBD) or uniqueness of samples was calculated using the adespatial package on macrofaunal and epifaunal species abundance data (Dray et al. 2017). Differences in LCBDs caused by oyster abundance were then analysed with a GLMM using PQL to estimate interference, fitted with a lognormal distribution. For macrofaunal analysis the fixed factor latitude and the random factor site were included to account for spatial variability and nested data. Owing to low replication, epifaunal analysis only included the random factor latitude to account for nested data along the spatial gradient. All data analyses were carried out in $\mathrm{R}$ version 3.4.1 (R Core Team 2017).

\section{Results}

\section{Effects of C. gigas on macro- and epifaunal assemblages}

A total of 74 taxa were identified in macrofaunal assemblages and 295 in epifaunal assemblages. Macrofaunal assemblages showed a significant interaction between oyster abundance and habitat type (Table 2a, Fig. 2a, b). Post
Table 2 Permutational multivariate analysis of variance (PERMANOVA) testing for the effects of oyster abundance (SACFOR), habitat type and exposure on (a) macrofaunal and (b) epifaunal assemblages

\begin{tabular}{lrrrr}
\hline & \multicolumn{1}{l}{ Df } & \multicolumn{1}{l}{$R^{2}$} & \multicolumn{1}{l}{$P$} \\
\hline (a) Macrofauna & & & & \\
Oyster abundance = OA & 3 & 12.51 & 0.05 & 0.665 \\
Habitat $=\mathrm{H}$ & 3 & 31.86 & 0.13 & 0.019 \\
Exposure = E & 2 & 21.32 & 0.06 & 0.999 \\
OA $\times \mathrm{H}$ & 8 & 4.24 & 0.05 & $<\mathbf{0 . 0 0 1}$ \\
OA $\times \mathrm{E}$ & 4 & 2.26 & 0.01 & 0.990 \\
H $\times \mathrm{E}$ & 1 & 4.68 & 0.01 & 0.388 \\
Residuals & 517 & & & \\
Total & 538 & & & \\
(b) Epifauna & & & & \\
Oyster abundance & 4 & 2.67 & 0.30 & 0.012 \\
Habitat & 3 & 1.99 & 0.17 & 0.189 \\
Exposure & 2 & 1.64 & 0.09 & 0.107 \\
OA $\times \mathrm{H}$ & 1 & 1.35 & 0.04 & 0.439 \\
OA $\times \mathrm{E}$ & 2 & 1.23 & 0.07 & 0.299 \\
Residuals & 12 & & & \\
Total & 24 & & & \\
\hline
\end{tabular}

Significant results $(P<0.01)$ are presented in bold

hoc tests were inconclusive but provided an indication that at muddy, rocky and sites with gravel, densities of oysters $>10 / \mathrm{m}^{2}$ featured a different macrofaunal assemblage structure than those with lower or no $C$. gigas abundance, while in mussel beds assemblage structure only differed when C. gigas was common $\left(1-9 / \mathrm{m}^{2}\right)$ or abundant $\left(10-99 / \mathrm{m}^{2}\right)$. Analysis on fourth-root-transformed data showed a similar interaction between oyster abundance and habitat type (PERMANOVA, $F(8538)=4.95, P<0.001)$; hence, shifts in macrofaunal assemblages are due to shifts of whole communities rather than few dominant species. Taxa driving these differences, as shown by SIMPER analysis, were a greater abundance of barnacles, red algae Chondrus crispus and the kelp Fucus vesiculosus in plots with abundant to superabundant densities of oysters. In contrast, the blue mussels $M$. edulis and the green algae $U$. lactuca occurred increasingly within plots of no or common presence of oysters (Online Resource 2, 3). The periwinkle Littorina sp., however, was present in high densities when oysters were superabundant, common or absent, but only in lower densities when oysters were abundant. Analysis on single species found that barnacles and $F$. vesiculosus showed interactions between habitat types and oyster abundances (Table 3). For barnacles this was also caused by differences in barnacle abundance between habitats, but mostly by differences within mussel beds, where the greatest barnacle abundance was found at oyster densities $>99 / \mathrm{m}^{2}$ (Table 3, Online Resource 3). Post hoc tests on $F$. vesiculosus were inconclusive, yet showed a 


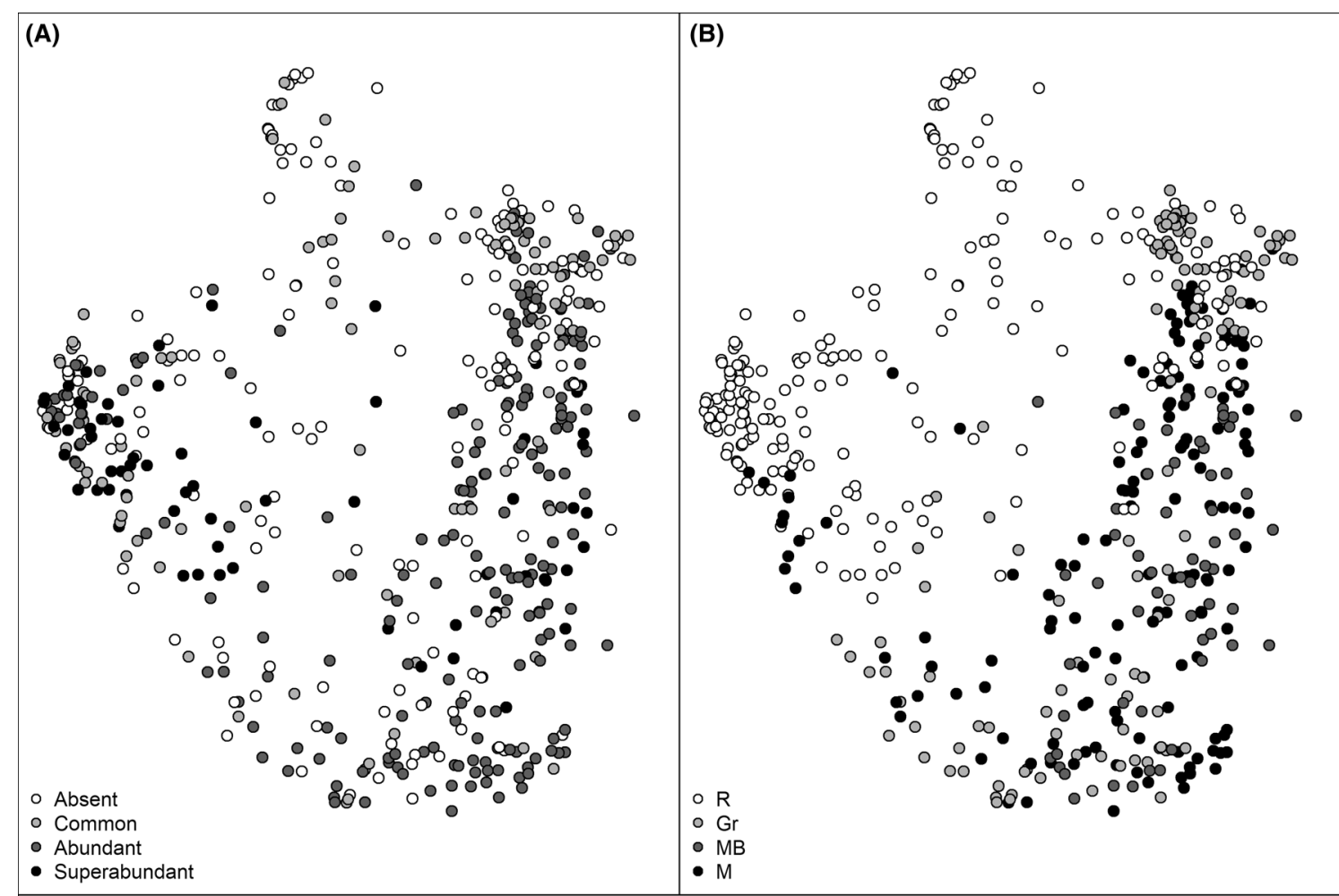

(C)

무

$\square$

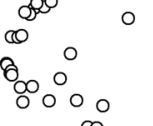

○ $\infty$

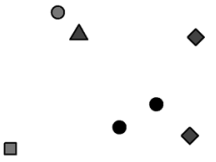

$\triangle$

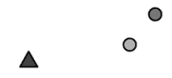

$\triangle$

0

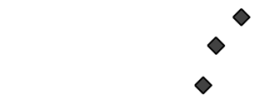

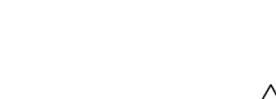

$\triangle$

$\square$

Fig. 2 Multi-dimensional scaling (MDS) plot of macrofaunal assemblages at all surveyed sites by (a) SACFOR scale and (b) habitat type: rocky (R), gravel (Gr), mussel bed (MB) and muddy (M). Oyster abundance (SACFOR) and habitat type for (c) epifaunal assemblages are represented by colour and different symbols, respectively.
Epifaunal diversity for control treatments was calculated from pooled $M$. edulis and $O$. edulis samples. Macrofaunal diversity for the category "Absent" was calculated from samples that did not contain any C. gigas 
Table 3 GLMM testing for the effect of oyster abundance and habitat type on the distribution of key species causing a shift in macrofaunal assemblages

\begin{tabular}{|c|c|c|c|}
\hline & $D f$ & $F$ & $P$ \\
\hline \multicolumn{4}{|l|}{ Cirripedia } \\
\hline Intercept & 1 & 78.97 & $<0.0001$ \\
\hline Oyster abundance $=\mathrm{OA}$ & 3 & 50.77 & $<0.0001$ \\
\hline Habitat $=\mathrm{H}$ & 3 & 0.87 & 0.482 \\
\hline $\mathrm{OA} \times \mathrm{H}$ & 9 & 2.03 & 0.035 \\
\hline \multicolumn{4}{|l|}{ Littorina sp. } \\
\hline Intercept & 1 & 22.08 & $<.0001$ \\
\hline Oyster abundance & 3 & 4.85 & 0.003 \\
\hline Habitat & 3 & 0.31 & 0.818 \\
\hline $\mathrm{OA} \times \mathrm{H}$ & 9 & 0.93 & 0.499 \\
\hline \multicolumn{4}{|l|}{ Mytilus edulis } \\
\hline Intercept & 1 & 47.29 & $<0.0001$ \\
\hline Oyster abundance & 3 & 1.68 & 0.171 \\
\hline Habitat & 3 & 0.04 & 0.990 \\
\hline $\mathrm{OA} \times \mathrm{H}$ & 9 & 0.79 & 0.625 \\
\hline \multicolumn{4}{|l|}{ Fucus vesiculosus } \\
\hline Intercept & 1 & 19.57 & $<.0001$ \\
\hline Oyster abundance & 3 & 0.38 & 0.771 \\
\hline Habitat & 3 & 2.28 & 0.124 \\
\hline $\mathrm{OA} \times \mathrm{H}$ & 9 & 3.28 & 0.001 \\
\hline \multicolumn{4}{|l|}{ Chondrus crispus } \\
\hline Intercept & 1 & 13.02 & 0.001 \\
\hline Oyster abundance & 3 & 0.43 & 0.734 \\
\hline Habitat & 3 & 0.61 & 0.622 \\
\hline $\mathrm{OA} \times \mathrm{H}$ & 9 & 1.44 & 0.166 \\
\hline \multicolumn{4}{|l|}{ Ulva lactuca } \\
\hline Intercept & 1 & 9.48 & 0.002 \\
\hline Oyster abundance & 3 & 1.40 & 0.243 \\
\hline Habitat & 3 & 2.43 & 0.108 \\
\hline $\mathrm{OA} \times \mathrm{H}$ & 9 & 0.97 & 0.468 \\
\hline
\end{tabular}

Sampling site was included in the analysis as random factor. Significant effects are presented in bold $(P<0.05)$

tendency for kelp abundance to increase with oyster abundance in all habitats except rocky shores where it decreased (Table 3, Online Resource 3). Increased densities of oysters also seemed to increase the abundance of Littorina sp. in all habitats except rocky shores, with the greatest abundance of periwinkles on sites with oyster density $>99 / \mathrm{m}^{2}$ (Table 3 , Online Resource 3). Specific analysis on M. edulis, U. lactuca and $C$. crispus revealed no impact of oyster abundance or habitat type on the distribution of these species (Table 3; Online Resource 3).

Epifaunal assemblages did not differ between $C$. gigas and $O$. edulis (GLMM, $F(1,7)=0.82, P=0.25)$ and their abundance (GLMM, $F(1,7)=1.98, P=0.17)$. Moreover, epifaunal assemblages did not differ with an increased abundance of $C$. gigas or between habitat type or wave exposure
(Table 2b, Fig. 2c). Although abundance of $C$. gigas was on the verge of significance, analysis on fourth-root-transformed data fortified the findings of the original analysis, with no shift in assemblages associated with oyster abundance (GLMM, $F(4,25)=1.88, P=0.046)$, habitat type (GLMM, $F(3,25), P=0.27)$, or wave exposure (GLMM, $F$ $(2,25)=0.99, P=0.22)$ at our $\alpha$-level of 0.01 .

\section{Impacts on a-diversity caused by C. gigas}

Macrofaunal diversity showed a significant interaction between oyster abundance and habitat type (GLMM, $F$ $(9,538)=2.28, P=0.016$; Fig. 3a), yet was not dependent on wave exposure $(\mathrm{GLMM}, F(2,538)=2.89, P=0.094)$. Post hoc tests showed that within muddy habitats, diversity associated with oyster densities $>99 / \mathrm{m}^{2}$ was higher than for lower oyster densities $\left(1-99 / \mathrm{m}^{2}\right)$. Epifaunal diversity was equally affected by increased densities of $C$. gigas (GLMM, $F(4,25)=9.06, P=0.001)$ and habitat type (GLMM, $F$ $(3,25)=8.88, P=0.002$; Fig. 3b). Here, sites with an oyster density between 0.1 and 0.9 oysters $/ \mathrm{m}^{2}$ showed greater diversity than those with oyster densities $>10 / \mathrm{m}^{2}$, but did not differ from diversity associated with mussel beds and $O$. edulis (Fig. 3b). Significant differences in epifaunal diversity found between habitat types can be mainly attributed to the high epifaunal diversity in mussel beds compared to those with soft or gravely substratum. Most importantly, subsequent analysis on epifaunal diversity associated with C. gigas and $O$. edulis showed no difference between the two species (GLMM, $F(1,7)=1.8, P=0.27$ ) at different oyster abundances $(\mathrm{GLMM}, F(1,7)=5.25, P=0.15)$.

\section{Effect of $C$. gigas on $\beta$-diversity}

For macrofaunal assemblages, uniqueness of site was greater in plots where oysters were common $\left(1-9 / \mathrm{m}^{2}\right)$ than in plots were $C$. gigas was absent, however neither differed from sites with greater oyster densities (GLMM, $F(3,538)=3.19$; $P=0.023$; Online Resource 4). Uniqueness of sites for macrofaunal assemblages also decreased with increasing latitude (GLMM, $F(1,538)=5.45 ; P=0.033)$. In contrast, epifaunal assemblages became more similar on sites with oyster densities $>99 / \mathrm{m}^{2}(\mathrm{GLMM}, F(4,20)=3.37 ; P=0.037$, Online Resource 4).

\section{Discussion}

The globally abundant oyster $C$. gigas is classified as invasive in many regions in the NE Atlantic, such as in the Wadden Sea and within the UK (Nehring 2006; Dutertre et al. 2010; Global Invasive Species Database 2015). Until now, its impacts have not been classified by a systematic sampling 


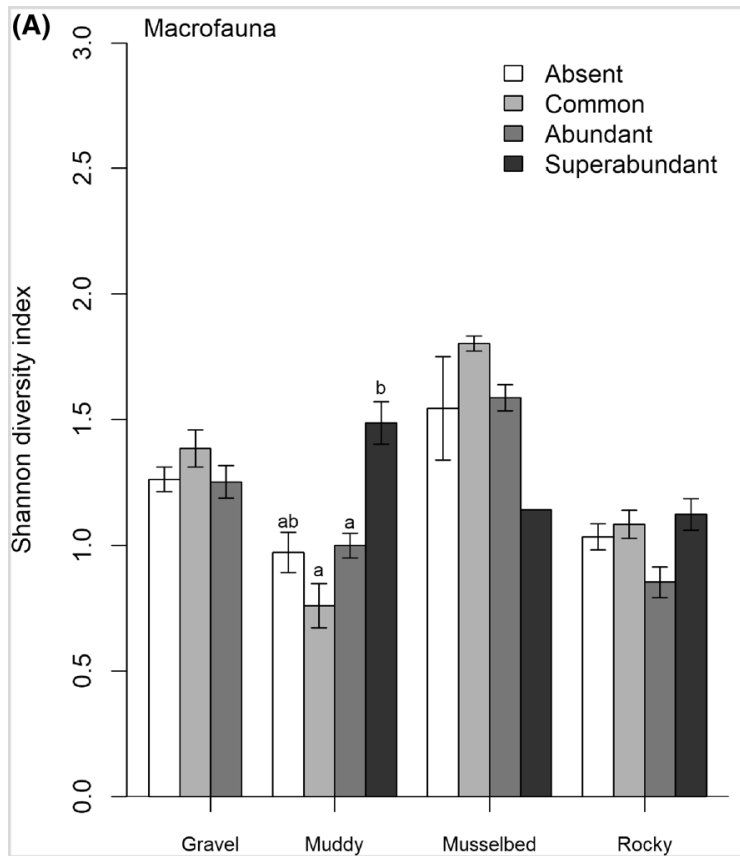

Fig. 3 Shannon diversity index (mean \pm SD) for (a) macrofauna and (b) epifauna by oyster abundance and habitat type according to the SACFOR scale. Samples with no C. gigas present (absent or control) are represented in white, and samples with $C$. gigas present in grey. Epifaunal diversity for control treatments was calculated from pooled $M$. edulis and $O$. edulis samples. Macrofaunal diversity for the cat-

design, incorporating context dependency and spatial scale. The current survey shows clearly that impact of $C$. gigas on macrofaunal assemblages is highly context dependent and changes with different oyster densities at different habitat types. On rocky shores for example, assemblages in plots with oyster densities $>10 \mathrm{~m}^{2}$ differed from plots containing less or no oysters in mussel beds; however, differences in macrofaunal assemblage structure were only perceived between plots where oysters were common or abundant. Impacts of $C$. gigas on macrofaunal diversity were restricted to muddy habitats, where diversity increased with increasing oyster density. Epifaunal assemblages were not affected by the presence of $C$. gigas compared to assemblages associated with $O$. edulis and $M$. edulis; epifaunal diversity, however, was highest at low densities of $C$. gigas and decreased with increasing densities. Similar epifaunal assemblages and biodiversity associated with low densities of $C$. gigas and $O$. edulis suggest functional equivalence of the two species in terms of habitat provision and biodiversity facilitation. Interestingly, while intermediate oyster density increased macrofaunal $\beta$-diversity, epifaunal species assemblages in different environmental regions showed an indication of becoming less unique with increasing $C$. gigas abundance.

The potential of $C$. gigas to alter species assemblages has been already widely known (Kochmann et al. 2008;

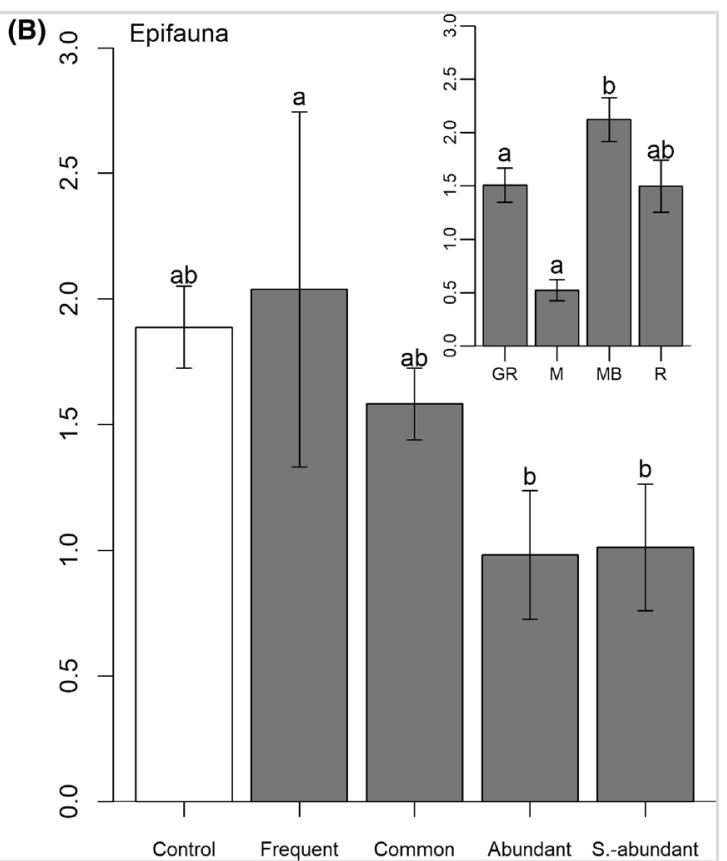

egory "Absent" was calculated from images that did not contain any C. gigas but might have contained native ecosystem engineers. Inset depicts epifaunal diversity associated with the different habitat types: gravel (GR), mud (M), mussel beds (MB) and rocky shores (R). Error bars represent standard deviations. Different lowercase letters denote significant differences between habitat types and oyster densities

Markert et al. 2009; Padilla 2010; Green and Crowe 2014; Norling et al. 2015). Comparisons with other native habitat engineers, such as the blue mussel M. edulis, have shown that these changes are dependent on the structural properties of the ecosystem engineer (Buschbaum et al. 2006; Gain et al. 2017). Similarities in epifaunal assemblages associated with both $C$. gigas and $O$. edulis support these findings and emphasise the importance of the unique biogenic habitat provided by oysters. These findings are also supported by a recent experiment comparing benthic assemblages associated with $C$. gigas and $O$. edulis at intertidal and subtidal hard substratum habitats (Zwerschke et al. 2016). In the past, most European shores would have included dense populations of native oysters O. edulis (Riesen and Reise 1982; Reise et al. 1989) and their associated benthic assemblages (Smyth and Roberts 2010). The recent decline of O. edulis populations resulted in altered benthic assemblage structure on these shores. The occurrence of wild $C$. gigas populations, albeit potentially harmful to $O$. edulis itself (Zwerschke et al., unpublished data), may help to re-establish coastal benthic communities to a former state. Here, we have increased the scope of previous understanding with regard to functional similarities between $C$. gigas and $O$. edulis and show that both oyster species support similar 
communities under varying environmental context when naturally co-occurring.

The effect of $C$. gigas differs between macrofaunal and epifaunal diversity and appears to be highly context dependent on habitat type. We suggest that the structural properties of the oysters were most important in soft sediment habitats for macrofauna and were underpinning the decrease in epifaunal diversity at increasing oyster densities. This is in concurrence with the theory that the greatest diversity is generally found at an intermediate level of structural complexity and that increased structural complexity reduces diversity, owing to a lower availability of settlement space (Snover and Commito 1998; Allouche et al. 2012). A similar pattern has often been observed for other ecosystem engineers as well. For example, an increase in structural complexity by densely packed turf algae reduces associated gastropod diversity (Kelaher 2003). The fact that diversity was similar between $C$. gigas and $O$. edulis raises the question whether diversity associated with formerly dense $O$. edulis beds would have followed a similar pattern. Unfortunately, low abundance of $O$. edulis did not allow for direct comparison of epifaunal diversity associated with both species for every abundance category. It is notable, however, that another study in Australia found similar epifaunal species richness associated with $C$. gigas and the native Saccostrea glomerata at different densities (Wilkie et al. 2012). Therefore, we suggest that the decline in epifaunal diversity associated with an increase in oyster density is the result of the decreased abundance of settlement space and an increased habitat fragmentation associated with such dense assemblages, which also occurs in other native ecosystem engineers (Tokeshi and Arakaki 2012).

Interactions between $C$. gigas and other key species seem to alter with habitat type. The abundance of barnacles for example increased with increasing oyster cover on rocky shores and mussel beds, but was greatest at low oyster densities at muddy sites and subsequently declined with increasing oyster cover. Furthermore, the abundance of $F$. vesiculosus and Littorina sp. generally increased with increasing oyster densities in all habitats, with the exception of rocky shores where their abundance decreased. Other species interaction may play a major role in determining such species abundance patterns. For example, is it likely that mechanisms interfering with successful recruitments, such as propagule pressure and abundance of grazers disturbing recently settled barnacle larvae or algae seedlings, may vary with time and location, while biological interactions may change with the maturity of oyster reefs (Jenkins et al. 2000; Holmes et al. 2005; Rezek et al. 2017). High densities of $C$. gigas may also limit the initial abundance of early colonizers such as barnacles possibly by ingestion of larval stages (Troost et al. 2008), but may prove to be a refuge from predation through the provision of complex three-dimensional structure for matured communities, thereby causing an accumulation of individuals over time (Grabowski 2004).

The spread of invasive species has often been linked to the loss of $\beta$-diversity along spatial scales (McKinney and Lockwood 1999; Piazzi and Balata 2007). Invasive ecosystem engineers, such as $C$. gigas, can cause a reduction in habitat heterogeneity by creating a similar habitat (e.g. oyster reefs) across different substratum types. This may subsequently lead to a reduced availability of habitat types, thereby decreasing $\beta$-diversity of associated communities (Piazzi and Balata 2007). To our knowledge, this was the first time the impact of $C$. gigas on $\beta$-diversity was observed over a large scale. When oysters were common, their abundance in different habitats may have contributed to a greater habitat heterogeneity by providing more and varying types of three-dimensional structure in the ecosystem, thus increasing $\beta$-diversity (Bouma et al. 2009). In contrast, greater oyster densities may reduce habitat heterogeneity, by providing a consistent three-dimensional space across different substratum types, which may have contributed to the observed decrease in epifaunal $\beta$-diversity (Bouma et al. 2009). A separate study found that high densities of $C$. gigas $\left(240\right.$ oysters $\left./ \mathrm{m}^{2}\right)$ can reduce $\beta$-diversity on a local scale (Green and Crowe 2014) and it is likely that the uniform habitat structure, created by such densities of $C$. gigas, attracts similar species assemblages and contributes to this loss of $\beta$-diversity. It must be borne in mind, however, that densities of $C$. gigas usually vary greatly across shores. In general, it is uncommon for $C$. gigas to populate entire shores and it is most likely that the oyster will be found in varying densities in a band between the mid and low intertidal zone (Kochmann et al. 2013). It is also unclear whether a similar $\beta$-diversity reducing effect can be observed for other ecosystem engineers populating different habitat types across Europe, such as the blue mussel M. edulis, and whether a similar reduction of $\beta$-diversity was associated with $O$. edulis when it used to be present in greater densities.

Including context dependency in surveys to classify the impacts of invasive species is extremely important, since the impacts may vary in different habitats, with different abiotic factors and different biotic interactions (Thomsen et al. 2011; Green and Crowe 2014; Kumschick et al. 2015). The present study is one of the few, spanning a variety of different habitat types and environmental conditions, which allows us to deduct more general predictions of the impact of $C$. gigas on native benthic assemblages and diversity. The most visible impact of $C$. gigas was limited to soft substratum habitats and areas with high densities of $C$. gigas. Here, we suggest that alterations of benthic community structure and diversity caused by the presence of $C$. gigas are owing to the provision of the unique habitat that is being created by oyster shells and is not specific to different oyster species. We propose that the presence of $C$. gigas will provide a 
habitat suitable for benthic communities formerly associated with declining $O$. edulis populations. In light of the global decline of ecologically valuable oyster reefs (Beck et al. 2011), and current restoration efforts (Laing et al. 2006; Lallias et al. 2010; Gercken and Schmidt 2014), the here observed functional similarity between low densities of $O$. edulis and $C$. gigas with regard to habitat provisioning may initiate a reconsideration of conservation goals in Europe. If the main objective is to create a three-dimensional structure that supports diversity and assemblages which are unique to oyster reefs, it may be worth to consider already abundant $C$. gigas populations as a valuable alternative to a more problematic re-introduction of $O$. edulis on European shorelines.

Acknowledgements We would like to thank Delphine Lallias for her help during fieldwork. For information on wild $C$. gigas locations, we would also like to thank Francis O'Beirn from the Marine Institute, Barry Quinn and his team at the Northern Irish Department of Aquaculture and Rural Development, Danielle Green and Judith Kochmann from UCD, Joss Wiggins from the Kent and Essex Inshore Fisheries and Conservation Authority, Roger Covey from Natural England, Mike Camplin from NRW, Jack Sewell from the Marine Biological Association, Nigel Mortimer as well as Joseph Mazurie and Stephane Pouvreau from Ifremer and Yann and François Cadoret from the Société Ostréiculteur François CADORET. We would also like to thank the two reviewers, whose comments have greatly improved the manuscript.

Funding This work was undertaken as part of the SEAFARE project, part funded by the ERDF Atlantic Area Transnational Programme (2007-2013) under Grant Agreement No. 2009-1/123.

\section{Compliance with ethical standards}

Conflict of interest The authors declare that they have no conflict of interest.

Ethical approval All applicable international, national and institutional guidelines for the use of animals were followed.

Open Access This article is distributed under the terms of the Creative Commons Attribution 4.0 International License (http://creativeco mmons.org/licenses/by/4.0/), which permits unrestricted use, distribution, and reproduction in any medium, provided you give appropriate credit to the original author(s) and the source, provide a link to the Creative Commons license, and indicate if changes were made.

\section{References}

Allouche O, Kalyuzhny M, Moreno-Rueda G et al (2012) Area-heterogeneity tradeoff and the diversity of ecological communities. Proc Natl Acad Sci 109:17495-17500

Anderson MJ, Walsh DCI (2013) PERMANOVA, ANOSIM, and the Mantel test in the face of heterogeneous dispersions: what null hypothesis are you testing? Ecol Monogr 83:557-574

Ballantine WJ (1961) A biologically-defined exposure scale for the comparative description of rocky shores. F Stud 1:1-19
Bayne BL, Ahrens M, Allen SK et al (2017) The proposed dropping of the genus Crassostrea for all pacific cupped oysters and its replacement by a new genus Magallana: a dissenting view. J Shellfish Res 36:545-547. https://doi.org/10.2983/035.036.0301

Beck MW, Brumbaugh RD, Airoldi L et al (2011) Oyster reefs at risk and recommendations for conservation, restoration, and management. Bioscience 61:107-116

Bellard C, Thuiller W, Leroy B, Genovesi P, Bakkenes M, Courchamp F (2013) Will climate change promote future invasions? Glob Change Biol 19(12):3740-3748

Bouma TJ, Olenin S, Reise K, Ysebaert T (2009) Ecosystem engineering and biodiversity in coastal sediments: posing hypotheses. Helgol Mar Res 63:95-106. https://doi.org/10.1007/s1015 2-009-0146-y

Breslow NE (2003) Whither PQL? Springer, New York

Buschbaum C, Chapman AS, Saier B (2006) How an introduced seaweed can affect epibiota diversity in different coastal systems. Mar Biol 148:743-754

Butchart SHM, Walpole M, Collen B, van Strien A, Scharlemann JPW, Almond REA, Baillie JEM, Bomhard B, Brown C, Bruno JF, Carpenter KE, Carr GM, Chanson J, Chenery AM, Csirke J, Davidson NC, Dentener F, Foster M, Galli A, Galloway JN, Genovesi P, Gregory RD, Hockings M, Kapos V, Lamarque J-F, Leverington F, Loh J, McGeoch MA, McRae L, Minasyan A, Morcillo MH, Oldfield TEE, Pauly D, Quader S, Revenga C, Sauer JR, Skolnik B, Spear D, Stanwell-Smith D, Stuart SN, Symes A, Tierney M, Tyrrell TD, Vie J-C, Watson RA (2010) Global Biodiversity: Indicators of Recent Declines. Science 328:1164-1168

Child AR, Laing I (1998) Comparative low temperature tolerance of small juvenile European, Ostrea edulis L., and Pacific oysters, Crassostrea gigas Thunberg. Aquaculture 29:103-113

Clarke KR, Warwick RM (2001) Change in marine communities: an approach to statistical analysis and interpretation, 2nd edn. Primer-E, Plymouth

Connor DW, Allen JH, Golding N et al (2004) The marine habitat classification for Britain and Ireland. Version 03.02. Joint Nature Conservation Committee, Peterborough

Crooks JA (2002) Characterizing ecosystem-level consequences of biological invasions: the role of ecosystem engineers. Oikos 97:153-166

Dray S, Blanchet G, Borcard D, Clappe S, Guenard G, Jombart T, Larocque G, Legendre P, Madi N, Wagner HH (2017) Adespatial: multivariate multiscale spatial analysis. $\mathrm{R}$ package version 0.0-9. https://CRAN.R-project.org/package=adespatial

Dubois SF, Commito JA, Olivier FF, Retière C (2006) Effects of epibionts on Sabellaria alveolata (L.) biogenic reefs and their associated fauna in the Bay of Mont Saint-Michel. Estuar Coast Shelf Sci 68:635-646

Dutertre M, Beninger PG, Barillé L et al (2010) Rising water temperatures, reproduction and recruitment of an invasive oyster, Crassostrea gigas, on the French Atlantic coast. Mar Environ Res 69:1-9

Eno NC, Clark RA, Sanderson WG (1997) Native marine species in British waters: a review and directory. Aquat Conserv Mar Freshw Ecosyst 8:719

Ferreira T, Rasband W (2011) ImageJ user guide. National Institutes of Health, Bethesda

Fridley AJD, Stachowicz JJ, Naeem S et al (2007) The invasion paradox : reconciling pattern and process in species invasions. Ecology $88: 3-17$

Gain IE, Brewton RA, Robillard MMR et al (2017) Macrofauna using intertidal oyster reef varies in relation to position within the estuarine habitat mosaic. Mar Biol 164:1-16

Gercken J, Schmidt A (2014) Current status of the European Oyster (Ostrea edulis) and possibilities for restoration in the German North Sea. Neu Broderstorf 
Global Invasive Species Database (2015) Crassostrea gigas. http:// www.issg.org/database/species/ecology.asp?si=797\&fr=1\&sts= sss\&lang $=$ EN. Accessed $1 \mathrm{Jul} 2015$

Grabowski JH (2004) Habitat complexity disrupts predator-prey interactions but not the trophic cascade on oyster reefs. Ecology 85:995-1004

Gray JS (1997) Marine biodiversity: patterns, threats and conservation needs. Biodivers Conserv 6:153-175. https://doi.org/10.3354/ meps 311175

Green DS (2017) Competitive interactions moderate the effects of elevated temperature and atmospheric $\mathrm{CO}_{2}$ on the health and functioning of oysters. Mar Ecol Prog Ser 582:93-103. https:// doi.org/10.3354/meps12344

Green DS, Crowe TP (2013) Physical and biological effects of introduced oysters on biodiversity in an intertidal boulder field. Mar Ecol Prog Ser 482:119-132

Green DS, Crowe TP (2014) Context- and density-dependent effects of introduced oysters on biodiversity. Biol Invasions 16:1145-1163

Guy-Haim T, Lyons DA, Kotta J, Ojaveer H, Queirós AM, Chatzinikolaou E, Arvanitidis C, Como S, Magni P, Blight AJ, OravKotta H, Somerfield PJ, Crowe TP, Rilov G (2018) Diverse effects of invasive ecosystem engineers on marine biodiversity and ecosystem functions: A global review and meta-analysis. Glob Change Biol 24:906-924

Herbert RJH, Humphreys J, Davies CJ et al (2016) Ecological impacts of non-native Pacific oysters (Crassostrea gigas) and management measures for protected areas in Europe. Biodivers Conserv 25:2835-2865

Hiscock K (1996) Marine nature conservation review: rational and methods. Joint Nature Conservation Committee, Peterborough

Hollander J, Blomfeldt J, Carlsson P, Strand A (2015) Effects of the alien Pacific oyster (Crassostrea gigas) on subtidal macrozoobenthos communities. Mar Biol 162:547-555. https://doi. org/10.1007/s00227-014-2604-6

Holmes SP, Walker G, Van Der Meer J (2005) Barnacles, limpets and periwinkles: the effects of direct and indirect interactions on cyprid settlement and success. J Sea Res 53:181-204

Hulme PE, Barrett SCH (2013) Integrating trait- and niche-based approaches to assess contemporary evolution in alien plant species. J Ecol 101:68-77

Huston MA (1997) Hidden treatments in ecological experiments: re-evaluating the ecosystem function of biodiversity. Oecologia 110:449-460

Jenkins SR, Aberg P, Cervin G et al (2000) Spatial and temporal variation in settlement and recruitment of the intertidal barnacle Semibalanus balanoides (L.) (Crustacea: Cirripedia) over a European scale. J Exp Mar Biol Ecol 243:209-225

Jones CG, Lawton JH, Shachak M (1997) Positive and negative effects of organisms as physical ecosystem engineers. Ecology 78:1946-1957

Katsanevakis S, Wallentinus I, Zenetos A et al (2014) Impacts of invasive alien marine species on ecosystem services and biodiversity: a pan-European review. Aquat Invasions 9:391-423

Kelaher BP (2003) Changes in habitat complexity negatively affect diverse gastropod assemblages in coralline algal turf. Oecologia 135:431-441

Kochmann J, Buschbaum C, Volkenborn N, Reise K (2008) Shift from native mussels to alien oysters: differential effects of ecosystem engineers. J Exp Mar Biol Ecol 364:1-10

Kochmann J, O'Beirn FX, Yearsley J, Crowe TP (2013) Environmental factors associated with invasion: modelling occurrence data from a coordinated sampling programme for Pacific oysters. Biol Invasions 15:2265-2279

Krassoi FR, Brown KR, Bishop MJ et al (2008) Condition-specific competition allows coexistence of competitively superior exotic oysters with native oysters. J Anim Ecol 77:5-15
Kumschick S, Gaertner M, Vila M et al (2015) Ecological impacts of alien species: quantification, scope, caveats, and recommendations. Bioscience 65:55-63

Laing I, Walker P, Areal F (2006) Return of the native: is European oyster (Ostrea edulis) stock restoration in the UK feasible? Aquat Living Resour 19:283-287

Lallias D, Boudry P, Lapègue $S$ et al (2010) Strategies for the retention of high genetic variability in European flat oyster (Ostrea edulis) restoration programmes. Conserv Genet 11:1899-1910. https://doi.org/10.1007/s10592-010-0081-0

Lallias D, Boudry P, Batista FM et al (2015) Invasion genetics of the Pacific oyster Crassostrea gigas in the British Isles inferred from microsatellite and mitochondrial markers. Biol Invasions 17:2581-2595

Laugen AT, Hollander J, Obst M, Strand A (2015) The Pacific oyster (Crassostrea gigas) invasion in Scandinavian coastal waters: impact on local ecosystem services. In: Canning-Clode $\mathbf{J}$ (ed) Biological invasions in aquatic and terrestrial systems: biogeography, ecological impacts, predictions, and management. De Gruyter Open, Berlin, pp 230-252. https://doi. org/10.1515/9783110438666

Lejart M, Hily C (2011) Differential response of benthic macrofauna to the formation of novel oyster reefs (Crassostrea gigas, Thunberg) on soft and rocky substrate in the intertidal of the Bay of Brest, France. J Sea Res 65:84-93

Lenth RV (2016) Least-squares means: the R package ismeans. J Stat Softw 69(1):1-33. https://doi.org/10.18637/jss.v069.i01

Mann R (1979) Some biochemical and physiological aspects of growth and gametogenesis in Crassostrea gigas and Ostrea edulis grown at sustained elevated temperatures. J Mar Biol Assoc UK 59:95-110

Markert A, Wehrmann A, Kröncke I (2009) Recently established Crassostrea-reefs versus native Mytilus-beds: differences in ecosystem engineering affects the macrofaunal communities (Wadden Sea of Lower Saxony, southern German Bight). Biol Invasions 12:15-32

McArdle BH, Anderson MJ (2001) Fitting multivariate models to community data: a comment on distance-based redundancy. Ecology 82:290-297

McKinney ML, Lockwood JL (1999) Biotic homogenization: a few winners replacing many losers in the next mass extinction. Trends Ecol Evol 14:450-453

Nehring S (2006) NOBANIS-Invasive Alien Species Fact Sheet Crassostrea gigas. From: Online database of the North European and Baltic Network on Invasive Alien SpeciesNOBANIS. http://www.nobanis.org. Accessed May 2007

Nic M, Jirat J, Kosata B (1997) IUPAC. Compendium of chemical terminology, 2nd edn. Blackwell Scientific Publications, Oxford

Nielsen M, Hansen BW, Vismann B (2017) Feeding traits of the European flat oyster, Ostrea edulis, and the invasive Pacific oyster, Crassostrea gigas. Mar Biol 164:1-10. https://doi. org/10.1007/s00227-016-3041-5

Norling P, Lindegarth M, Lindegarth S, Strand A (2015) Effects of live and post-mortem shell structures of invasive Pacific oysters and native blue mussels on macrofauna and fish. Mar Ecol Prog Ser 518:123-138

Oksanen J, Blanchet FG, Friendly M, Kindt R, Legendre P, McGlinn D, Minchin PR, O’Hara RB, Simpson GL, Solymos P, Henry M, Stevens H, Szoecs E and Wagner HH (2017) Vegan: community ecology package. R package version 2.4-4. https://CRAN.Rproject.org/package $=$ vegan

Padilla DK (2010) Context-dependent impacts of a non-native ecosystem engineer, the Pacific oyster Crassostrea gigas. Integr Comp Biol 50:213-225 
Piazzi L, Balata D (2007) The spread of Caulerpa racemosa var. cylindracea in the Mediterranean Sea: an example of how biological invasions can influence beta diversity. Mar Environ Res 65:50-61

R Core Team (2017) R: a language and environment for statistical computing. R Foundation for Statistical Computing, Vienna, Austria. https://www.R-project.org/

Reise K, Herre E, Sturm M (1989) Historical changes in the benthos of the Wadden Sea around the island of Sylt in the North Sea. Helgoländer Meeresuntersuchungen 43:417-433

Rezek RJ, Lebreton B, Roark EB et al (2017) How does a restored oyster reef develop? An assessment based on stable isotopes and community metrics. Mar Biol 164:1-17

Riesen W, Reise K (1982) Macrobenthos of the subtidal Wadden Sea: revisited after 55 years. Helgoländer Meeresuntersuchungen 35:409-423

Rinde E, Tjomsland T, Hjermann DØ et al (2016) Increased spreading potential of the invasive Pacific oyster (Crassostrea gigas) at its northern distribution limit in Europe due to warmer climate. Mar Freshw Res 68:252-262

Robins PE, Tita A, King JW, Jenkins SR (2017) Predicting the dispersal of wild Pacific oysters Crassostrea gigas (Thunberg, 1793) from an existing frontier population-a numerical study. Aquat Invasions 12:117-131

Salvi D, Mariottini P (2016) Molecular taxonomy in 2D: a novel ITS2 rRNA sequence-structure approach guides the description of the oysters' subfamily Saccostreinae and the genus Magallana (Bivalvia: Ostreidae). Zool J Linn Soc 179:263-276

Shatkin G, Shumway SE, Hawes R (1997) Considerations regarding the possible introduction of the Pacific oyster (Crassostrea gigas) to the Gulf of Maine: a review of global experience. J Shellfish Res 16:463-477

Shelmerdine RL, Mouat B, Shucksmith RJ (2017) The most northerly record of feral Pacific oyster Crassostrea gigas (Thunberg, 1793) in the British Isles. BioInvasions Rec 6:57-60

Smyth D, Roberts D (2010) The European oyster (Ostrea edulis) and its epibiotic succession. Hydrobiologia 655:25-36
Snover M, Commito JA (1998) The fractal geometry of Mytilus edulis L. spatial distribution in a soft-bottom system. J Exp Mar Biol Ecol 223:53-64

Syvret M, Fitzgerald A, Hoare P (2008) Development of a Pacific oyster aquaculture protocol for the UK-Technical Report. Sea Fish Industry Authority

Thomsen MS, Wernberg T, Olden JD et al (2011) A framework to study the context-dependent impacts of marine invasions. J Exp Mar Biol Ecol 400:322-327

Tokeshi M, Arakaki S (2012) Habitat complexity in aquatic systems: fractals and beyond. Hydrobiologia 685:27-47. https://doi. org/10.1007/s10750-011-0832-z

Troost K, Kamermans P, Wolff WJ (2008) Larviphagy in native bivalves and an introduced oyster. J Sea Res 60:157-163

Vitousek PM (1990) Biological invasions and ecosystem processes: towards an integration of population biology and ecosystem studies. Oikos 57:7-13

Vitousek PM, D’Antonio CM, Loope LL, Westbrooks R (1996) Biological invasions as global environmental change. Am Sci 84:468

Wilkie EM, Bishop MJ, O'Connor WA (2012) Are native Saccostrea glomerata and invasive Crassostrea gigas oysters' habitat equivalents for epibenthic communities in south-eastern Australia? J Exp Mar Biol Ecol 420-421:16-25

Zuur AF, Ieno EN, Walker NJ et al (2009) Mixed effects models and extensions in ecology with R. Springer Science + Business Media, New York

Zwerschke N, Emmerson MC, Roberts D, O'Connor NE (2016) Benthic assemblages associated with native and non-native oysters are similar. Mar Pollut Bull 111:305-310. https://doi.org/10.1016/j. marpolbul.2016.06.094

Zwerschke N, Kochmann J, Crowe TP et al (2017) Co-occurrence of native $O$ strea edulis and non-native Crassostrea gigas revealed by monitoring of intertidal oyster populations. J Mar Biol Assoc United Kingdom 1-10. https://doi.org/10.1017/S00253154170014 48 